\title{
Vesical nephrogenic adenoma: an unusual presentation of a bladder tumour
}

\author{
Carlos Martínez-Sanchíz, MD; Jesús Martínez-Ruiz, MD;* Pedro J. Anguita-Fernandez, MD;* \\ José M. Giménez-Bachs, MD;"* Manuel Atiénzar-Tobarra, MD;+ Julio Antonio Virseda Rodríguez, MD; * \\ Antonio S. Salinas-Sánchez, $M D^{*}$
}

*Urology Service, Complejo Hospitalario Universitario de Albacete, Faculty of Medicine, Universidad de Castilla La Mancha, Albacete, Spain; ${ }^{\dagger}$ Anatomical Pathology Service, Complejo Hospitalario Universitario de Albacete, Faculty of Medicine, Universidad de Castilla La Mancha, Albacete, Spain

Cite as: Can Urol Assoc J 2011;5(5):E79-E80; D01:10.5489/cuaj.11005

\begin{abstract}
Vesical nephrogenic adenoma is a rare, benign entity that appears most commonly in middle-aged males. Its etiology is unknown, but it has been linked to chronic irritating factors, such as infection, trauma, urological surgery, kidney stones, foreign bodies and chemical agents, such as Bacille Calmette-Guerin. We report 2 new cases with a history of transurethral resection of the bladder and the prostate and a history of prolonged voiding symptoms. In both cases, the findings of encysted tubular structures lined with flattened cuboidal cells without atypia were consistent with the diagnosis of vesical nephrogenic adenoma.
\end{abstract}

\section{Introduction}

Vesical nephrogenic adenoma is a rare, benign entity that appears most commonly in middle-aged males. Several hundred cases have been reported worldwide..$^{1-5}$ Its etiology is unknown, but it has been linked to chronic irritating factors, such as infection, trauma, urological surgery, kidney stones, foreign bodies and chemical agents, such as Bacille Calmette-Guerin (BCG). Davis published the first case in the literature in 1949. ${ }^{6}$ The term "nephrogenic adenoma" was coined in 1950 by Friedman and Kuhlenbeck, who noted the resemblance of this lesion to the renal tubule. ${ }^{1}$ Two cases of vesical nephrogenic adenoma will be presented.

\section{Case 1}

A 60-year-old male with a diagnosis of chronic renal failure was seen for severe voiding symptoms and hematuria. The patient was on hemodialysis and had a history of a transurethral resection of the prostate and a bladder diver- ticulectomy after a transurethral resection of bladder neck. An ultrasound scan revealed a raised intra-vesical lesion. Cystoscopy showed multiple trabeculae and diverticulae of the bladder and, in the left side, a superficial papillary lesion $3 \mathrm{~cm}$ in diameter, which was resected. The histological study showed the presence of focal ducts lined with cuboidal epithelium without atypia, located in areas of urothelial denudation (Fig. 1), findings compatible with vesical nephrogenic adenoma. Currently, the patient is asymptomatic, undergoes regular check-ups and is waiting for a kidney transplant due to end-stage renal disease.

\section{Case 2}

An 80-year-old male was seen for a consultation for hematuria. The patient had a history of two previous transurethral resections for a bladder tumour and benign prostatic hyperplasia. An ultrasound revealed a small lesion on the right side. Cystoscopy showed a 1-cm lesion in the perimeatic area, which was resected. The histological study showed encysted tubular structures lined with flattened cuboidal cells, consistent with vesical nephrogenic adenoma (Fig. 2 ). The patient is currently being monitored, and his condition is well-controlled.

\section{Discussion}

Nephrogenic adenoma (or papillary tubular adenoma) is a rare, benign metaplastic lesion. ${ }^{3}$ Its most characteristic location is in the bladder, especially in the trigone, but it is also found, to a lesser extent, in the urethra and ureters. Chronic bladder irritation by foreign bodies, trauma, urological surgery, prolonged instrumentation of the urinary tract, intravesical instillation of BCG, calculi and genitourinary tuberculosis have been implicated in the etiology of nephrogenic adenoma. ${ }^{1}$ Cases have also been reported in the 


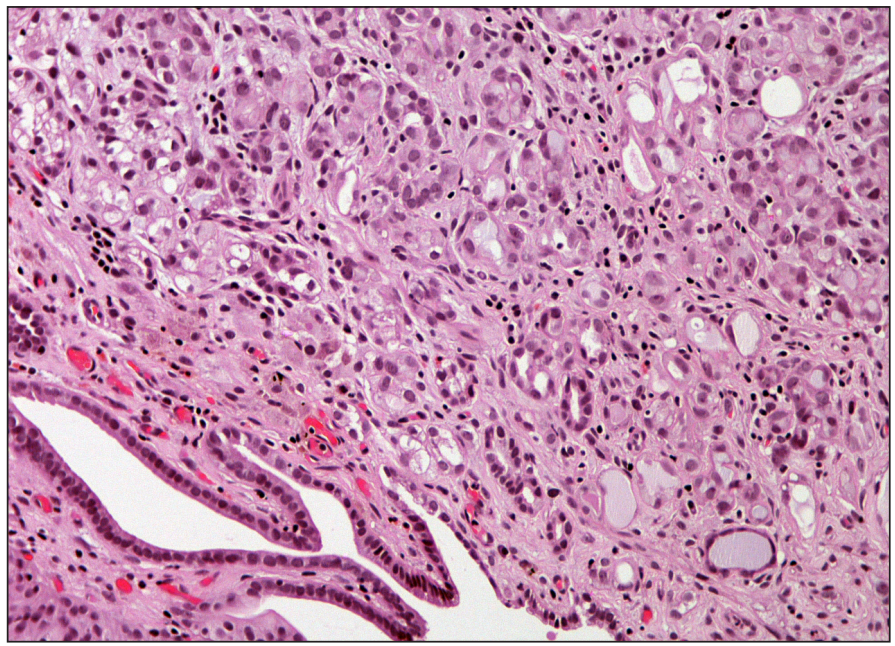

Fig. 1. Focal ducts lined with cuboidal epithelium.

bladders of patients who have received renal transplants and in patients who are immunosuppressed for other reasons. Nephrogenic adenoma is regarded as a benign lesion, and no correlation with transitional cell carcinoma has been identified. ${ }^{2}$ Its clinical presentation is often dominated by persistent voiding symptoms, and there also may be hematuria. There is very frequently a history of urological surgery. ${ }^{2}$ One of the cases reported here had chronic renal failure, and the other had a history of transurethral resection of the bladder and prostate and of prolonged voiding symptoms.

The study of these 2 patients involved obtaining urine cultures, performing a cystoscopic examination and resecting any lesions that appeared.

Diagnosis is anatomopathological and is characterized by the presence of ducts lined with epithelium combined with the absence of atypia and mitotic activity, positive extracellular PAS staining and prominent membranes associated with the presence of interspersed inflammatory cells. ${ }^{4}$

In spite of the benign nature of this condition, patients must be closely monitored because the rate of recurrence of nephrogenic adenoma is high. Out-patient monitoring should include urine cytology, ultrasound and cystoscopy. ${ }^{2}$

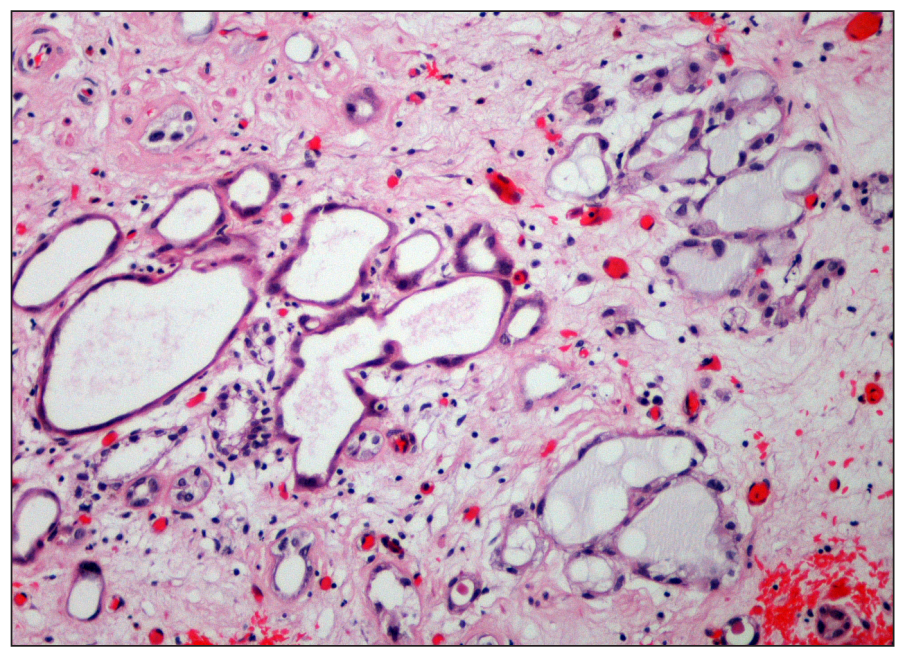

Fig. 2. Encysted tubular structures lined with flattened cuboidal cells.

This paper has been peer-reviewed.

\section{References}

1. Friedman NB, Kuhlenbeck H. Adenomatoid tumor of the bladder reproducing renal structures (nefrogenic adenoma). J Urol 1950;64:657-70.

2. Chen C-S, Cheng C-L. Nephrogenic adenoma of the urinary bladder: clinical experience and review of the literature. J Chin Assoc 2006;69:166-8.

3. Llanes González L, Martin Osés E, Fernández González I, et al. Adenoma nefrogénico vesical: descripción de un caso. Arch Esp Urol 1998;51:923-5.

4. Grasa Lanau V, Guarch Troyas R, Montesino Semper M. Adenoma nefrogénico: estudio de nueve casos, incluyendo uno de uretra en varón de 14 años. Arch Esp Urol 1998;51:138-44.

5. Crook TJ, Mead Z, Vadgama B, et al. A case series of nephrogenic adenoma of the urethra and bladder in children: review of this rare diagnosis, its natural history and management, with reference to the literature. J Pediatr Urol 2006;2:323-8.

6. Davis TA. Hamartoma of the urinary bladder. Northwest Med 1949;48:182-5.

Correspondence: Dr. Carlos Martínez-Sanchíz, Servicio de Urología. Complejo Hospitalario Universitario, Hermanos Falcó, 37, Albacete 02006, Spain; cmsanchiz@hotmail.com

Competing interests: None declared. 